\title{
Role of Microwave Ablation in Treatment of Lung Tumors
}

\author{
EMAD H.A. EMARA, M.Sc.*; MONA O. ABOELEZZ, M.D.**; \\ HOSSAM EL DIN M. ABDEL RAHMAN, M.D.**; SAMEH S. BIOMY, M.D.** and THOMAS J. VOGL, M.D.***
}

The Department of Radiology, Faculty of Medicine, Kafrelsheikh University*, The Department of Radio Diagnosis, Faculty of Medicine, Zagazig University**, Egypt and The Department of Diagnostic \& Interventional Radiology, Faculty of Medicine, Johan Wolfgang Goethe University, Germany***

\begin{abstract}
Background: Image-guided percutaneous thermal ablation is a common excellent alternative option for treatment of nonoperable primary and metastatic lung tumors. These techniques are based on heating effect on the tissue around a percutaneous applicator causing coagulative necrosis of the tumor cells. Microwave Ablation (MWA) is a commonly used locoregional interventional procedure in treatment of pulmonary tumors with satisfactory outcome.

Aim of Study: The aim of the study was to evaluate the role of CT-guided microwave ablation of inoperable lung tumors.

Subjects and Methods: This study was carried out at Diagnostic \& interventional Radiology Department, Goethe University Hospitals, Frankfurt, Germany during the period from April 2017 to March 2020, included 40 patients with 52 lung malignant lesions, underwent CT-guided microwave ablation. All patients were subjected to complete clinical examination, pre-procedural laboratory investigations \& imaging evaluation. Post ablation follow-up by chest CT was done after 24 hours, three, six, nine months, one year and every 6 months onwards to determine treatment response. Patients were either adequately ablated (no residual tumor activity) or had local progression (residual tumor activity).
\end{abstract}

Results: Forty-four malignant lesions $(84.6 \%)$ showed complete response to treatment and 8 lesions $(15.4 \%)$ had local progression (residual activity). The median time to local tumor progression was 8.3 months. The median survival was 32 months for patient underwent MWA according to the Kaplan-Meier test. The overall survival rate at 1, 2, and 3 years was $97.5 \%, 90 \%$, and $82.5 \%$, respectively. Successful tumor ablation was significantly more frequent for lesions with a maximal axial diameter of $3 \mathrm{~cm}$ or smaller $(p=.0001)$ There were no deaths during the procedure and the mortality rate within 6 months after ablation was $0 \%$. Early postablation complications included pneumothorax (13.5\%), pulmonary hemorrhage $(9.6 \%)$ and postablation syndrome $(3.85 \%)$, Pleural Effusion (3.85\%), Hemoptysis (3.85\%). Manual evacuation was done in 3 cases out of 7 sessions complicated by pneumothorax. No significant long-term complications were detected.

Correspondence to: Dr. Emad H.A. Emara, The Department of Radiology, Faculty of Medicine, Kafrelsheikh University, Egypt
Conclusion: Percutaneous CT-guided microwave ablation therapy for management of pulmonary tumors is safe and effective minimally invasive option and can improve local tumor control and survival rate in patients who are not candidate for surgical resection.

Key Words: Microwave ablation (MWA) - Radiofrequency ablation (RFA) - CT-guided - Local tumor control - Lung tumors - Non-Small Cell Lung Cancer (NSCLC).

\section{Introduction}

LUNG cancer remains the leading cause of cancer death. Pneumonectomy or lobectomy with hilar and mediastinal lymph node sampling is the gold standard treatment and offers the best option for curing stage 1/2 Non-Small Cell Lung Cancer (NSCLC) [1,2]

Unfortunately, only $15 \%$ of patients present with stage $1 / 2$ disease, and many of these do not meet the pulmonary physiologic criteria for lobar resection. In addition to lung cancer, pulmonary metastases are present in 25-30\% of patients dying from all types of cancer. For some patients with oligometastatic pulmonary disease, metastectomy is associated with an improvement in survival. External beam radiation traditionally has been offered as the alternative to surgical resection for NSCLC or pulmonary metastatic disease. Unfortunately, the five-year survival following radiation for stage 1 and 2 NSCLC remains low at 15-20\%, with local recurrence being the most common type of failure [1-3]

Thermal ablation offers a therapeutic option to improve local tumour control and survival in patients with early-stage NSCLC or with limited metastatic disease from non-lung primaries, who are not candidates for surgical intervention, either because of poor cardiopulmonary reserve, anatomic 
constraints limiting resection, failure of traditional therapies or refusal of operative approaches [4].

Tumor heating ablation under the guidance of image has been proved to be one treatment method with definite effects [5], and the method of treating inoperable pulmonary malignancies with Microwave Ablation Therapy (MWA) is one of the new minimally invasive techniques popular in recent years [6].

Electromagnetic waves were used in Microwave Ablation (MWA) to produce tissue heating effects and would result in a much larger zone of active heating when compared with that of Radiofrequency Ablation (RFA), which made percutaneous microwave ablation therapy (MWA) a more precise and more reliable method in treating malignancies in many tissues [7-9].

MWA produce more tissue heating with larger ablation zone than radiofrequency ablation due to its greater convection profile in lung and less severe heat sink effects. Furukawa et al., also found that tissues around the electrodes changed immediately after MWA, that is fibrosis and thickening of collagenous fiber [10]. The ablated pulmonary tissues would be replaced by scar fibrous tissues after 6 months [10]

MW ablation therapy is a safe therapeutic tool for the treatment of primary and metastatic pulmonary neoplasms. The efficacy of treatment is determined mainly by pre-ablation tumour size and location in relation to the hilum [4].

The purpose of the current study was to evaluate the efficacy of microwave ablation in treatment of inoperable pulmonary tumors.

\section{Patients and Methods}

This study is a prospective interventional study. The study was approved by the Local Ethical Committee board. It was carried out in institute of Diagnostic and Interventional Radiology, Johann Wolfgang Goethe/Frankfurt University Hospital, Frankfurt am Main, Germany, during the period from April 2017 to March 2020.

A total of 40 patients with 52 primary (9) and metastatic lung lesions (Colon carcinoma (19), Breast carcinoma (10), HCC (6), RCC (4), Endometrial carcinoma (2), Parotid carcinoma (2)). (Table 12), ranging from 0.5 to $5 \mathrm{~cm}$ (Table 7 ) were included in this study and underwent CT-guided microwave ablation. They were (19) males and (22) females, their ages ranged from 34 to 83 years (mean age $\pm \mathrm{SD}$ is $63.8 \pm 14.6$ years). (Tables 1,2 ) Figs. $(1,2)$.

\section{Inclusion criteria:}

1- Patients have lost the opportunity of surgical resection (inoperable) or cannot endure surgical treatment because of other diseases.

2- Patients with primary or metastatic pulmonary tumor (Table 12).

3- Metastases after pneumonectomy or recurrent metastases after surgical resection.

4- Number of lesions less than 5 or lesion diameter less than $5 \mathrm{~cm}$.

5- Patient refusing to undergo surgery.

6- Histopathological confirmation of malignancy (Table 4).

7- Adequate baseline bleeding profile including the following laboratory values:

a- Platelet count $>75,000 / \mathrm{cc}$.

b- International normalizing ration $<1.5$.

c- Prothrombin time $<15$ seconds.

d- Activated Partial Thromboplastin Time (PTT) $<45$ seconds.

Exclusion criteria:

1- Uncontrolled primary malignancy (active disease or metastases to other organs).

2- Patients with serious failure of the function of important organs (heart, liver, lung, and kidney).

3- Patients with hilum lesions and companied by larger cavity.

4- Patients with central-type pulmonary malignancies and companied by severe obstructive pneumonia, patients with cancer involving main bronchus.

5- Patients with pulmonary malignancies transferred to neck and thoracic vertebra.

6- Patients with pulmonary diffuse metastatic lesions.

7- Lesions more than 5, diameter more than $5 \mathrm{~cm}$.

8- Septicemia and coagulopathy (International Normalized Ratio (INR) > 1.8, or a platelet count $>75,000 / \mathrm{ml}$ ).

All patients were subjected to the following:

1- Pre-ablation assessment and patient preparation for ablation:

The assessments of patients who are candidates to microwave ablation were performed by the inter- 
ventional radiologist in conjunction and the referring physician. The self-referred patients were assessed by a thoracic multidisciplinary tumor board including interventional radiologist, thoracic surgeons, pulmonology and medical oncology physicians.

A comprehensive clinical history was then taken including previous imaging, biopsy, operations, treatment plans and medications.

Physical examination was performed; recent imaging studies reviewed, and the indications, risks, complications and benefits of the procedure were discussed with the patients in detail.

Before ablation, malignancy has to be confirmed histologically to patients whom diagnosed as earlystage primary lung cancer (non-small-cell) with no lymph node metastasis and not candidates for surgery as a result of associated comorbidity. Diagnosis is confirmed using endoscopy, transbronchial biopsy or percutaneous biopsy.

Histological confirmation is often unnecessary if lesion morphology is typical for patients with pulmonary metastases who are not candidates for curative resection of metastases or those with a limited number of pulmonary metastases, as part of palliative care.

Pre-procedural laboratory investigations including complete blood count and coagulation profile that consisted of bleeding time, Partial Thromboplastin Time (PTT) and International Normalized Ratio (INR) were performed prior to the ablation procedure.

Anticoagulant or antiplatelet medications were stopped from 3 days to one week before the procedure to avoid the risk of bleeding. Repeat coagulation profile studies were performed before the procedure to verify normal coagulation prior the ablation procedure. Prophylactic antibiotics were not routinely given.

Patients underwent CT scanning in the supine position immediately before treatment to confirm the number and size of lesions. The ablation parameters, including applicator length, and number, as well as the position of the patient and site of puncture, were planned on the basis of tumor size and anatomical location.

\section{2- Microwave ablation procedure:}

Lung microwave ablations were performed using CT fluoroscopic guidance (Somatom Sensation 64; Siemens, Erlangen, Germany using the following parameters: $5-\mathrm{mm}$ collimation, $30 \mathrm{mAs}$, $120 \mathrm{kV}$, and 5-mm section thickness) with Covidien microwave system "EmprintTM Ablation System with ThermosphereTM Technology, Medtronic, USA".

The ablation procedure was performed under complete aseptic conditions. Combination sedation and analgesia with fentanyl citrate (1 packilogram of body weight) and midazolam hydrochloride $(0.010-0.035 \mathrm{mg} / \mathrm{kg})$ were administered in a stepwise fashion under guidance of the interventionist until the patient was drowsy and tolerating the pain associated the ablation procedure.

Continuous electrocardiography, pulse oximetry, and blood pressure monitoring was done throughout the procedure.

The patient was positioned on the CT table according to the location of the lesion to achieve the shortest accessible path to the lesion in the position most tolerable to the patient either in supine, prone or lateral position.

Pre-ablation CT chest without contrast was done to locate the lesion to be ablated.

All ablation procedures were performed by using microwave antennae (shaft length, 15, 20 or $30 \mathrm{~cm}$; radiating section, $3.7 \mathrm{~cm})$. Ablation time was recorded for all procedures. The antenna was introduced in a stepwise manner achieving an optimal zone of overlapping ablation ensuring that there was an adequate safety margin around the ablated lesions. The duration of ablation ranged from 530 minutes.

The Covidien microwave applicators (antennae) were applied through a single pleural puncture. Applicator location was visualized by using CT fluoroscopy to ensure optimal positioning of the radiating part of the antennae within the lesion.

The criteria for optimal entrance planning were based on the location of the lesion and its relation to the pleura, major bronchi, and pulmonary blood vessels. Adequate skin disinfection of the area of skin entry was performed, followed by injection of $10 \mathrm{ml}$ of local anaesthetic $0.5 \%$ mepivacaine (Scandicain, AstraZeneca, Wedel, Germany).

Periodic CT fluoroscopic scanning of the tumor was performed to reassess adequate positioning of the applicator and to monitor associated complications. Treatment was continued as long as required and safely tolerated. If complications occurred because of the microwave ablation, the severity and extent of the complications determined termi- 
nation of the ablation session and appropriate intervention if required.

To prevent seeding of malignant cells in the needle track during removal of the needle electrode and to induce local hemostasis of the electrode track, needle track coagulation was routinely performed at the end of the procedure using ablation thermal energy during withdrawing the needle Figs. $(3,4)$.

\section{3- Post ablation follow-up protocol:}

- A spiral control CT of the thorax immediately following the intervention serves directly for the final evaluation and for the detection of possible complications.

- A thorax radiograph in two positions was performed $6 \mathrm{~h}$ after the procedure.

- Follow-up CT was performed at the following periods:

a- 24h post ablation: As the first control study post ablation to assess further morphological changes, and in order to exclude remote post ablation complications before patient discharge.

b- 4-6 weeks post ablations.

c- 3, 6, 9- and 12-months post ablation and finally at 6-months intervals using multi-detector row helical CT scanner (SOMATOM Sensation 64, Siemens, Erlangen, Germany; 30mAs/120 $\mathrm{kV} / 5 \mathrm{~mm}$ slice thickness).

Both unenhanced and contrast material enhanced chest CT scanning was performed. CT protocol was: $(100 \mathrm{~mL}$ of Omnipaque was administered at a flow rate of $2-3 \mathrm{~mL} / \mathrm{sec}$. Image acquisition began 30 seconds after contrast agent injection).

- Patients with unclear response were additionally evaluated using PET-CT to determine and exclude any residual metabolic activity in the ablation bed.

- Response to treatment is considered when the ablated lesion decreased in size over time with no contrast uptake and local progression either due to residual or recurrent disease was considered when the lesion became of larger size or expressed morphological changes in its shape such as protrusion or, irregular, nodular or eccentric focus arising from the margin in addition to denovo focus showing contrast uptake ( $>15 \mathrm{HU})$. A thin symmetric rim of peripheral enhancement of less than $5 \mathrm{~mm}$ wide observed up to 6 months after ablation was considered a sign of benign peritu- moral enhancement. This determining factor was based on evaluating parameters used by previous lung ablation studies in our hospital and from different institutes.

\section{4- Re-ablation of lesions failed after initial abla- tion:}

Re-ablation of lesions that did not respond to initial microwave ablation therapy was performed after clinical justification and exclusion of systemic tumor spread. Re-ablation of the initially nonresponsive lesions was performed between 1 month and 12 months after the initial ablation. Re-ablation was performed in 4 lesions out of 8 failed lesions post MWA. Secondary tumor control post reablation revealed $50 \%(2 / 4)$ secondary success rate post MW ablation with no evidence of tumor residual or recurrence within 3 to 9 month followup period after re-ablation.

\section{Statistical analysis:}

- Analysis of data was done using SPSS version (SPSS version 25) (Statistical Package for the Social Sciences) (IBM, 2017).

- Radiological evaluation of pre-procedural, intraprocedural, and post-procedural CT images was done. The minimum follow-up period for all patients involved in the study was 6 months.

- Survival times were calculated using the KaplanMeier.

- The log-rank test (Cox-Mantel $\chi^{2}$ value) was used to determine the significance of differences between patient survival rates.

- $p$-value of less than 0.05 was considered to indicate a statistically significant difference for all analyses.

\section{Results}

A total of 40 patients with 52 lung malignant lesions were included in this study (Table 3). They were 9 primary and 43 metastatic lesions (Table 4). Forty-four lesions (84.6\%) showed complete response to treatment and eight lesions (15.4\%) had local progression (residual activity) during the follow-up period ranging from 6 to 36 months (Table 5), Figs. $(3,4)$.

The median time to local tumor progression was 8.3 months. The overall median survival was 32 months for patient underwent MWA according to the Kaplan-Meier test. The overall survival rate at 1,2 , and 3 years was $97.5 \%, 90 \%$, and $82.5 \%$, respectively (Table 6) \& Fig. (5). 
The median survival time for local control group was 32 months. The median survival time for local progression group was 26 months.

The survival rate is significantly higher with local control group than local progression group using Log Rank test ( $p=0.025$ ) Fig. (6).

Successful tumor ablation was significantly more frequent for lesions with a maximal axial diameter of $3 \mathrm{~cm}$ or smaller than for lesions greater than $3 \mathrm{~cm}$ in maximal axial diameter $(p=.018)$. (Table 7).

There was a statistically significant relation between the mean volume of lesions before ablation and treatment outcome post ablation with larger tumor volume before ablation in local progression group than responsive group (0.028) (Table 8). Also there was significant relation between lesion location in relation to lung hilum and treatment outcome with better outcome seen in peripheral lesions $(p=0.019)$ (Table 9).

There was no significant relation between lesion location in relation to pulmonary vessels and the shape of the lesions before ablation with treatment outcome ( $p=0.341 \& p=0.168$ respectively) (Tables $10,11)$.There was no significant relation between different pathological type of primary or secondary pulmonary tumor and treatment outcome (Table

Early postablation complications included pneumothorax $(13.5 \%)$, pulmonary hemorrhage $(9.6 \%)$ and postablation syndrome (3.85\%), Pleural Effusion $(3.85 \%)$, Hemoptysis $(3.85 \%)$. There were no deaths during the procedure and the mortality rate within 6 months after ablation was $0 \%$. No significant long-term complications were seen (Table 13). Conservative management was done in 4 cases $\&$ manual evacuation was done in 3 cases out of 7 sessions complicated by pneumothorax and no intercostal tube was inserted (Table 14).

There was significant risk factors associated with development of pneumothorax during ablation procedure as patient age with more liability in patients above 60 years $(p=0.027)$, comorbid lung disease as emphysema ( $p=0.041)$, preablation tumor size with more occurrence of pneumothorax in lesions of tumor size $<3 \mathrm{~cm}(p=0.016)$, location of lesions with high incidence in lower lung lesions $(p=0.045)$ and needle track traversing aerated lung parenchyma for a distance $>2.6 \mathrm{~cm}(p=0.018)$ and traversing a major pulmonary fissure by ablation needle $(p=0.036)$ (Table 15).
Table (1): Gender distribution of studied patients.

\begin{tabular}{lcc}
\hline Gender & Frequency & Percent \\
\hline Male & 19 & 47.5 \\
Female & 21 & 52.5 \\
\hline Total & 40 & 100.0 \\
\hline
\end{tabular}

Table (2): Age distribution of studied patients.

\begin{tabular}{lcl}
\hline Age & Frequency & Percent \\
\hline $31-40$ & 2 & 5 \\
$50-41$ & 5 & 12.5 \\
$60-51$ & 6 & 15 \\
$70-61$ & 13 & 32.5 \\
$80-71$ & 11 & 27.5 \\
$81-90$ & 3 & 7.5 \\
\hline Total & 40 & 100 \\
\hline
\end{tabular}

Table (3): Number of lesions per patient.

\begin{tabular}{lcc}
\hline Number of lesions & Patients number & Total lesions \\
\hline Single lesion & 32 & 32 \\
Two lesions & 4 & 8 \\
Three lesions & 4 & 12 \\
\hline Total & 40 & 52 \\
\hline
\end{tabular}
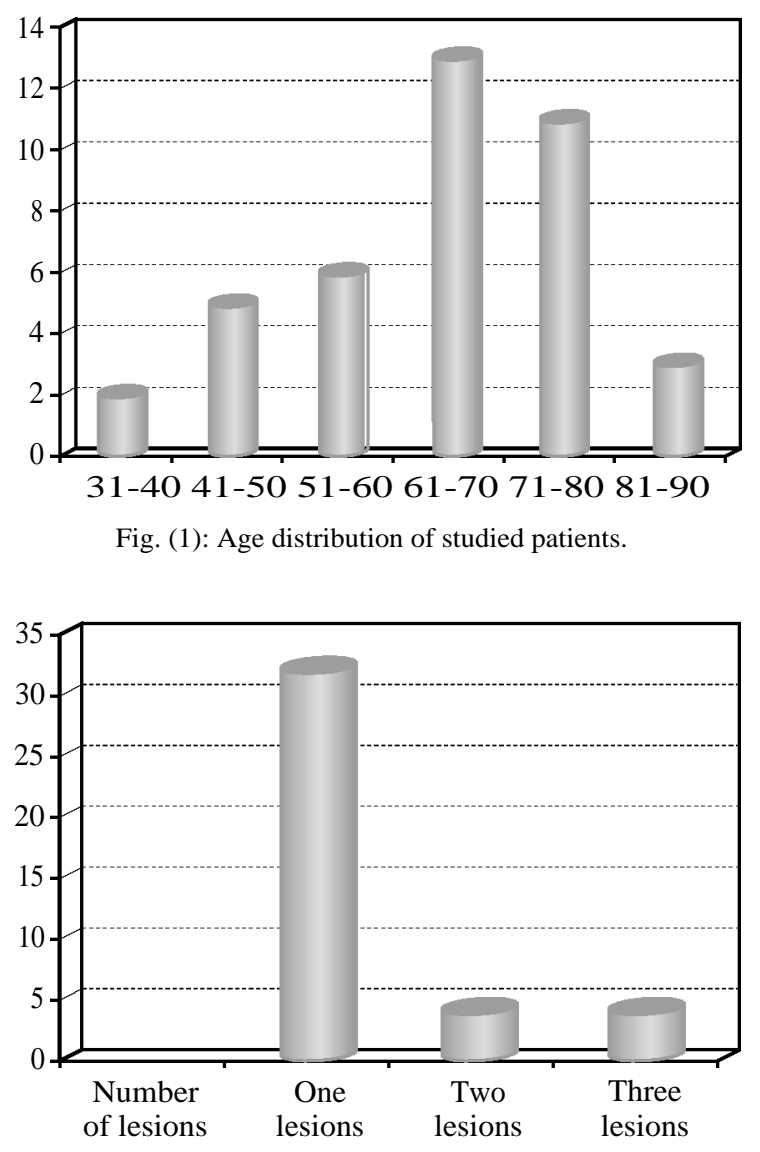

Fig. (2): The number of lesions per patients. 


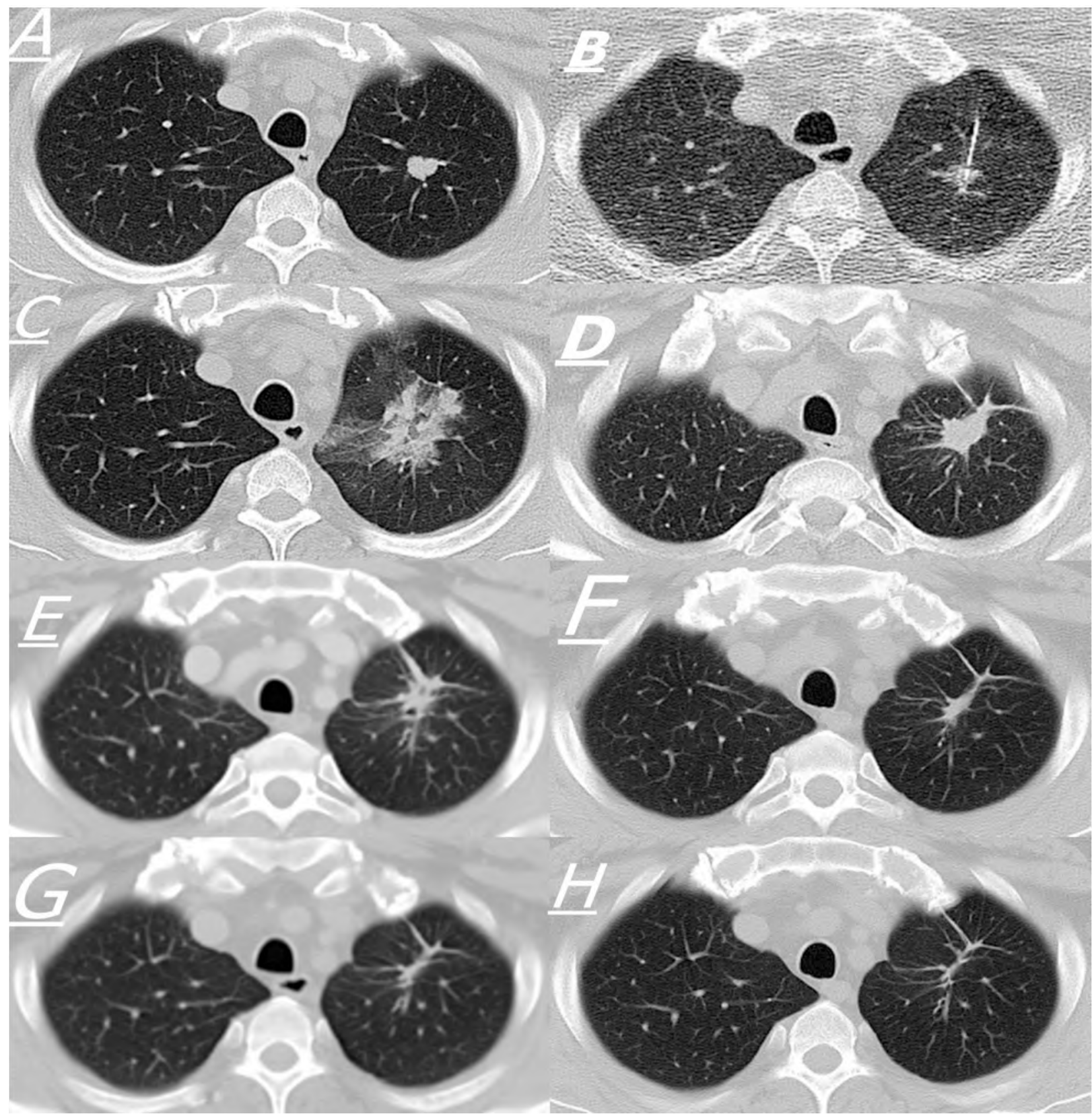

Fig. (3): (A-H): Microwave ablation of lung metastases from renal cell carcinoma in 69 years old male patient. (A) Left upper lung lesion measuring $1.1 \mathrm{X} 1.4 \mathrm{~cm}$. (B) Ablation needle inside the lesion during microwave ablation process. (C) Ablation zone 24 hours after microwave ablation in the form of ground glass opacity exceeding the lesion with safety margin. (D-H) Serial CT images at 1, 3, 6 , 9,12 months after ablation respectively after ablation showing regression of lesion with progressive scaring denoting complete resolution.

Table (4): Type of lesion: (Primary or secondary).

Table (5): Treatment outcome.

\begin{tabular}{lcclrr}
\hline Type of lesion & Frequency & Percent & Outcome & Frequency & Percent \\
\hline Primary & 9 & 17.3 & $\begin{array}{l}\text { - Local tumor response (control) } \\
\text { - Local tumor progression } \\
\text { (recurrence or residue) }\end{array}$ & $\begin{array}{c}44 \\
8\end{array}$ & 84.6 \\
Metastatic & 43 & 82.7 & Total & 52 & 15.4 \\
\hline Total & 52 & 100.0 & & &
\end{tabular}




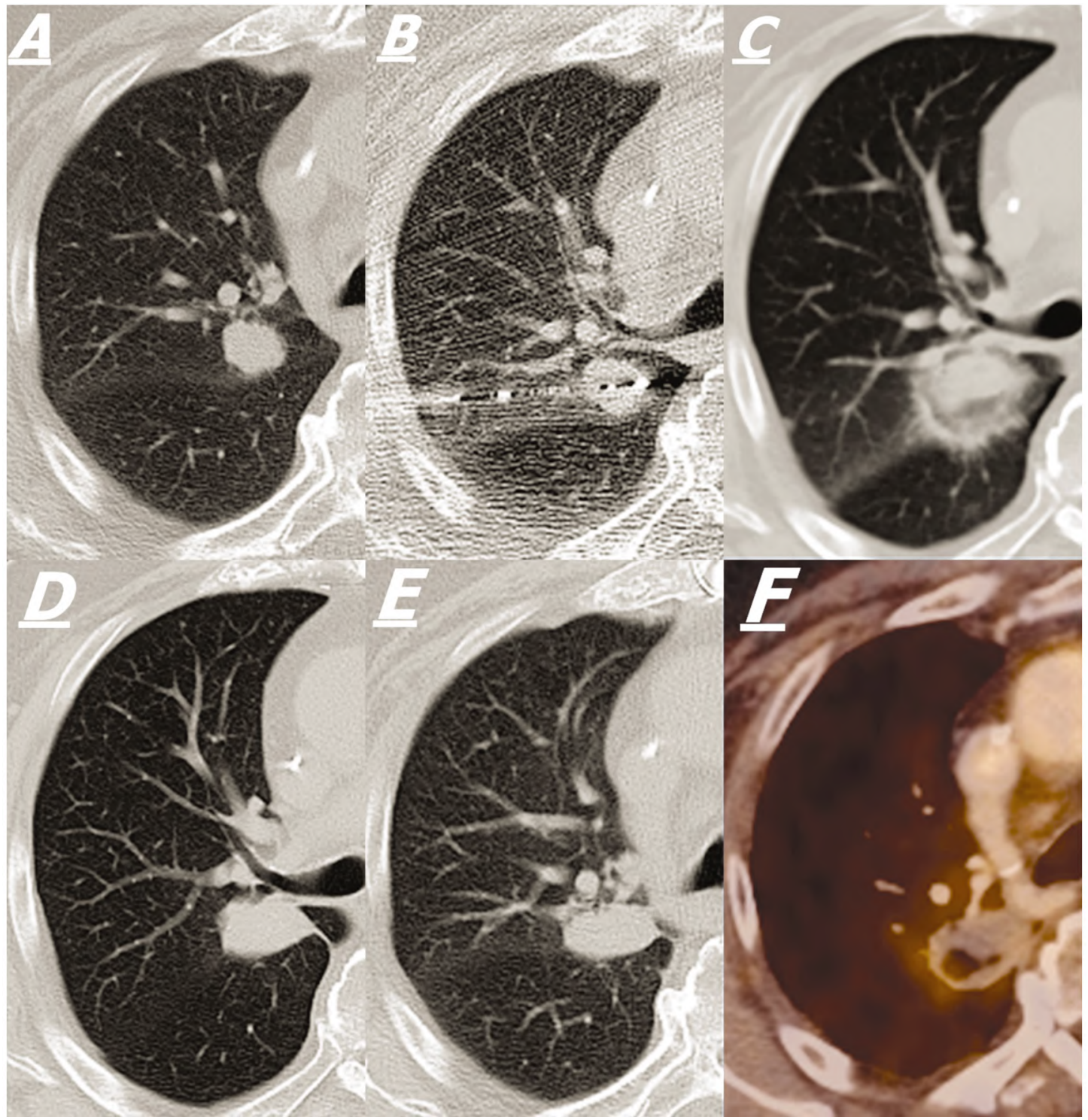

Fig. (4): (A-F): Microwave ablation of colorectal metastases of 75 years old male. (A) CT image show lesion measuring $2.1 \mathrm{X} 2 \mathrm{~cm}$ seen posterior segment right upper lung lobe. (B) Ablation needle inside lesion during ablation procedure. (C) Ablation zone of ground glass opacity covering the lesion. (D) CT follow-up after 3 months showing no contrast enhancement of the lesion. (E) CT follow-up after 3 months showing no contrast enhancement of the lesion. (F) PET-CT scan after 9 months showing no metabolic activity of ablated lesion denoting complete response.

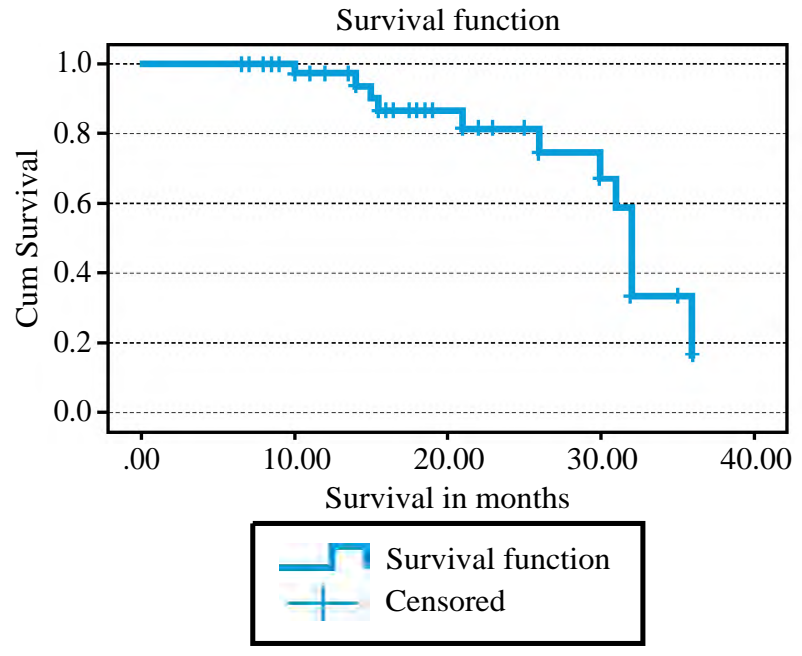

Fig. (5): Kaplan-Meier curve of the overall survival rate of all patients treated with MWA.

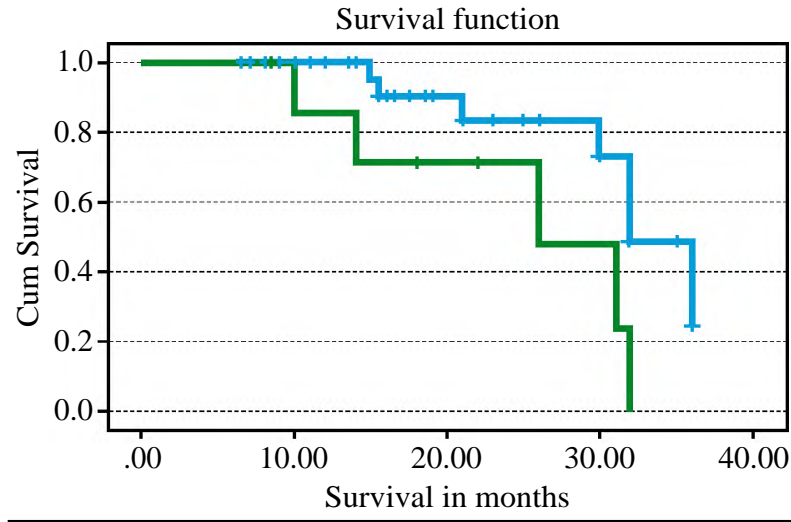

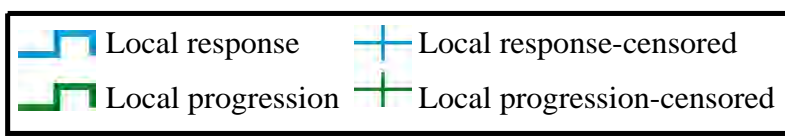

Fig. (6): Kaplan-Meier curve of the survival rate of local response (Blue line) and local progression (Green line) groups treated with MWA. 
Table (6): Means and medians for survival time.

\begin{tabular}{|c|c|c|c|c|c|c|c|c|}
\hline \multirow{3}{*}{ Local control } & \multicolumn{4}{|c|}{ Mean a } & \multicolumn{4}{|c|}{ Median } \\
\hline & \multirow{2}{*}{ Estimate } & \multirow{2}{*}{ Std. Error } & \multicolumn{2}{|c|}{$95 \%$ confidence interval } & \multirow{2}{*}{ Estimate } & \multirow{2}{*}{ Std. Error } & \multicolumn{2}{|c|}{$95 \%$ confidence interval } \\
\hline & & & Lower Bound & Upper Bound & & & Lower Bound & Upper Bound \\
\hline Local response & 31.379 & 1.740 & 27.790 & 34.789 & 32.000 & 2.018 & 28.054 & 35.946 \\
\hline Local progression & 24.619 & 3.611 & 17.541 & 31.698 & 26.000 & 8.042 & 10.273 & 41.763 \\
\hline Overall & 29.683 & 1.569 & 26.609 & 32.758 & 32.000 & .521 & 30.979 & 33.021 \\
\hline
\end{tabular}

a: Estimation is limited to the largest survival time if it is censored.

Table (7): Size of lesions before ablation.

\begin{tabular}{lccc}
\hline Size range & \multicolumn{2}{c}{ Treatment outcome } & \\
\cline { 2 - 3 } & $\begin{array}{c}\text { Local } \\
\text { response }\end{array}$ & $\begin{array}{c}\text { Local tumor } \\
\text { progression }\end{array}$ & $p$-value \\
\hline Less than $3 \mathrm{~cm}$ & 41 & 3 & $0.018^{*}$ \\
3 to $5 \mathrm{~cm}$ & 3 & 5 & 52 \\
\hline Total & 44 & 8 & 52 \\
\hline
\end{tabular}

Table (8): Volume of lesions before ablation.

\begin{tabular}{llll}
\hline & \multicolumn{2}{c}{ Treatment outcome } & $p$ - \\
\cline { 2 - 3 } & $\begin{array}{c}\text { Local } \\
\text { response }\end{array}$ & $\begin{array}{c}\text { Local tumor } \\
\text { progression }\end{array}$ & value \\
\hline Mean tumor volume (cc) & 1.2 & 4.8 & $0.028^{*}$ \\
Range of tumor volume (cc) & $0.1-13.9$ & $0.3-61.3$ & \\
\hline
\end{tabular}

Table (9): Location in relation to lung hilum.

\begin{tabular}{lccc}
\hline & \multicolumn{2}{c}{ Treatment outcome } & \\
\cline { 2 - 3 } & $\begin{array}{c}\text { Local } \\
\text { response }\end{array}$ & $\begin{array}{c}\text { Local tumor } \\
\text { progression }\end{array}$ & $p$-value \\
\hline Central & 2 & 5 & $0.019^{*}$ \\
Peripheral & 42 & 3 & 52 \\
\hline Total & 44 & 8 & 52 \\
\hline
\end{tabular}

Table (10): Location in relation to pulmonary vessels.

\begin{tabular}{|c|c|c|c|}
\hline \multirow{2}{*}{$\begin{array}{l}\text { Relation to } \\
\text { pulmonary vessels } \\
\text { (within } 5 \mathrm{~mm} \text { ) }\end{array}$} & \multicolumn{2}{|c|}{ Treatment outcome } & \multirow[b]{2}{*}{$p$-value } \\
\hline & $\begin{array}{l}\text { Local } \\
\text { response }\end{array}$ & $\begin{array}{l}\text { Local tumor } \\
\text { progression }\end{array}$ & \\
\hline No & 29 & 5 & 0.341 \\
\hline Yes & 15 & 3 & \\
\hline Total & 44 & 8 & 52 \\
\hline
\end{tabular}

Table (11): Shape of the lesions.

\begin{tabular}{lccc}
\hline \multirow{2}{*}{ Tumor margin } & \multicolumn{2}{c}{ Treatment outcome } & \\
\cline { 2 - 3 } & $\begin{array}{c}\text { Local } \\
\text { response }\end{array}$ & $\begin{array}{c}\text { Local tumor } \\
\text { progression }\end{array}$ & $p$-value \\
\hline Coarse irregular & 28 & 5 & 0.186 \\
Fine irregular & 16 & 3 & 52 \\
\hline Total & 44 & 8 & 52 \\
\hline
\end{tabular}

Table (12): Pathology of different types of pulmonary lesions and its influence on ablation outcome.

\begin{tabular}{|c|c|c|c|c|}
\hline \multirow[b]{2}{*}{ Tumor type } & \multicolumn{2}{|c|}{ Treatment outcome } & \multirow[b]{2}{*}{ Total } & \multirow{2}{*}{$\begin{array}{c}p- \\
\text { value }\end{array}$} \\
\hline & $\begin{array}{l}\text { Loca } \\
\text { respor }\end{array}$ & $\begin{array}{l}\text { tumor } \\
\text { ression }\end{array}$ & & \\
\hline Bronchial carcinoma & 8 & 1 & 9 & 0.41 \\
\hline Colon carcinoma & 17 & 2 & 19 & 0.42 \\
\hline Breast carcinoma & 8 & 2 & 10 & 0.34 \\
\hline $\mathrm{HCC}$ & 5 & 1 & 6 & 0.41 \\
\hline $\mathrm{RCC}$ & 3 & 1 & 4 & 0.39 \\
\hline Endometrial carcinoma & 2 & 0 & 2 & 0.51 \\
\hline Parotid adenocarcinoma & 1 & 1 & 2 & 0.68 \\
\hline Total & 44 & 8 & 52 & \\
\hline
\end{tabular}

Table (13): Complications occurred during the microwave ablation therapy.

\begin{tabular}{lll}
\hline Complication & $\begin{array}{c}\text { Frequency } \\
\text { per session }\end{array}$ & Percent \\
\hline Pneumothorax: & $(7 / 52)$ & $(13.5)$ \\
$\quad$ Mild & $4 / 7$ & 57.1 \\
$\quad$ Moderate & $3 / 7$ & 42.9 \\
$\quad$ Severe & $0 / 9$ & 0.0 \\
Pulmonary hemorrhage & $(5 / 52)$ & 9.6 \\
Pleural effusion & $(2 / 52)$ & 3.85 \\
Hemoptysis & $(1 / 52)$ & 1.9 \\
Surgical emphysema & $(1 / 52)$ & 1.9 \\
Postablation syndrome & $(1 / 52)$ & 1.9 \\
Pulmonary infection & $(0 / 52)$ & 0.0 \\
Burn at the site of the ablation punctures & $(0 / 52)$ & 0.0 \\
Death during the procedure & $(0 / 52)$ & 0.0 \\
\hline Total ablation session with complication & $(17 / 52)$ & 32.65 \\
\hline
\end{tabular}

Table (14): Management of pneumothorax complicating ablation therapy.

\begin{tabular}{lcc}
\hline Management method & Frequency & Percent \\
\hline Conservative management & $(4 / 7)$ & 57.1 \\
Manual evacuation & $(3 / 7)$ & 42.9 \\
Intercostal chest tube & $(0 / 9)$ & 0.0 \\
\hline
\end{tabular}


Table (15): Risk factors for development of pneumothorax in patients treated by MWA.

\begin{tabular}{|c|c|c|c|}
\hline \multirow{2}{*}{ Risk factors } & \multicolumn{2}{|c|}{ Pneumothorax } & \multirow{2}{*}{$\begin{array}{c}p \\
\text { value }\end{array}$} \\
\hline & Yes & No & \\
\hline \multicolumn{4}{|l|}{ Age: } \\
\hline$>60$ & 5 & 22 & \multirow[t]{2}{*}{$0.027 *$} \\
\hline$<60$ & 2 & 11 & \\
\hline \multicolumn{4}{|l|}{ Gender: } \\
\hline Male & 4 & 15 & \multirow[t]{2}{*}{0.43} \\
\hline Female & 3 & 18 & \\
\hline \multicolumn{3}{|l|}{ Underlying emphysema: } & \multirow{3}{*}{$0.041 *$} \\
\hline Yes & 4 & 19 & \\
\hline No & 3 & 26 & \\
\hline \multicolumn{4}{|l|}{ Tumor size: } \\
\hline$<3 \mathrm{~cm}$ & 4 & 40 & \multirow[t]{2}{*}{$0.016^{*}$} \\
\hline$>3 \mathrm{~cm}$ & 3 & 5 & \\
\hline \multicolumn{4}{|l|}{ Tumor location: } \\
\hline Upper lung zone & 2 & 27 & \multirow[t]{2}{*}{$0.045^{*}$} \\
\hline Lower \& middle zones & 5 & 18 & \\
\hline \multicolumn{4}{|l|}{$\begin{array}{l}\text { Ablation track length } \\
\text { traversing aerated lung. }\end{array}$} \\
\hline $0-2.5 \mathrm{~cm}$ & 2 & 39 & \multirow{2}{*}{$0.018 *$} \\
\hline$>2.6 \mathrm{~cm}$ & 5 & 6 & \\
\hline \multicolumn{4}{|l|}{$\begin{array}{l}\text { Ablation needle traversing } \\
\text { maior pulmonarv fissure. }\end{array}$} \\
\hline Yes & 2 & 1 & \multirow[t]{2}{*}{$0.036^{*}$} \\
\hline No & 5 & 45 & \\
\hline
\end{tabular}

\section{Discussion}

Lung cancer is a major cause of cancer-related death worldwide. Lobectomy is the standard treatment for early stage lung cancer. However, many patients with lung cancers are not fit for lobectomy because of poor pulmonary reserve, associated comorbidities, or other risk factors [11]. These patients are usually treated in a multidisciplinary fashion, with systemic therapies and radiation therapy being the most commonly used modalities. However, all these treatments rarely provide a cure or good long-term survival outcomes [12].

Recently, many studies have adopted thermal ablation, including RFA and MWA, for treatment of tumors. Kwan et al., reported no difference in Overall Survival (OS) following sub-lobar resection or thermal ablation for comparable elderly patients with stage I non-small cell lung cancer [11]

Several studies have evaluated the safety and efficacy of CT-guided MWA in lung cancer patients [12]. This procedure is now proved to be an important tool in the treatment of primary and secondary lung tumors which offers patients a repeatable, effective, safe and low-cost treatment for lung malignancies either after or concurrently with radiotherapy or systemic therapy. The NSCLC guideline published by National Comprehensive Cancer Network (NCCN) recently suggested that ablation could be an option for patients with unresectable stage IA NSCLC, selected patients with multiple pulmonary lesions and those with tumor recurrence in the lung [13]

Both microwave and Radiofrequency ablations have same benefits, however MWA has some more advantages including; less time needed for procedure, higher temperature for target lesions, cellular necrosis volumes are bigger, option to use multiple antennae, accessibility to lesions in proximity to vascular structures less than $3 \mathrm{~mm}$ in diameter and/or having cystic components with less incidence of the heat-sink effect as well as less intraprocedural pain [14]

In our prospective study, we revealed the safety, efficacy, and prognostic value of MWA for treatment of inoperable lung tumors and whether lesions characteristics can affect the ablation efficacy/ success rate or not through prospective approach.

In the current study about $84.4 \%$ of the ablated lesions showed complete local response while $15.6 \%$ of lesions showed local tumor progression either due to due to tumor residue or recurrence. Ierardi et al., showed that 29\% (9/31) of lesions showed local recurrence after treatment on followup with the rest of lesions $71 \%$ (22/31) showed no residual tissue on follow-up [14] . Also, Vogl et al., stated that $73.1 \%(95 / 130)$ of lesions showed complete successful ablation while $26.9 \%(35 / 130)$ of lesions had failed ablation either related to residual tumor or recurrent disease during follow-up [15] In their study on 69 patients, Lu et al., showed local progression occurred in 15 cases $(21.74 \%)$ on his study in 69 cases with pulmonary malignancy [16]. Also, Zheng et al., found that the local progression rate was $19.1 \%$ (35 of 183) during their retrospective study of MWA in 183 patients [17] Healey et al., found among the 108 patients with single lung malignancy, that primary technical success was achieved in $80 \%(n=86)$ while the 22 patients had residual tumor on follow-up [18].

The percentage of progressive disease in our study and these other studies is more or less the same. In the other hand the complete local tumor response showed difference in percentage of lesions achieving complete response among different studies, this can be due to difference in assessment methods of defining local tumor response as in our study it is considered mainly with change in ablated 
lesions morphological characters not only according to contrast enhancement of the tissue.

The mean time of tumor progression/detection was 8.3 months (range: $3-12$ months). The median survival rate of the patients who underwent MWA was 32 months. No procedure related mortality occurred. The overall one, two, three years survival rates were $97.5 \%, 90 \%$ and $82.5 \%$ respectively. Higher survival rates were detected in patients with tumor free-state after successful ablation and local tumor control in comparison to patients with local progression. This difference in survival rates was statistically significant $(p=0.038)$. This may reflect the clinical significance of ablation therapy of pulmonary neoplasms in the improvement of patients' survival.

The current study showed that there was no statistically significant relation between the ablation outcome and both of tumor origin either primary or metastatic as well as the pathological type of metastatic disease and this conclusion is supported by Vogl et al., Healey et al., and Ierardi et al., as they also found no significant relation between pathological type of pulmonary tumor and treatment outcome. Perhaps this attributed to the inclusion of multiple histopathologic subgroups with a small sample size of some histopathologic types $[14,15,18]$

The results of the microwave ablation procedure were primarily determined by the preablation lesion size. The primary determinant for successful ablation is the achievement of an adequate ablation zone and associated safety margins. This is to ensure eradication of marginal microscopic tumor infiltration in the surrounding parenchyma [15]

In the current study about $84.6 \%$ of the ablated lesions were less than or equal to $3 \mathrm{~cm}$ in size while $15.4 \%$ of ablated lesions were from 3 to $5 \mathrm{~cm}$ in size and this result are the same as that of Vogl et al., 2011 on microwave ablation of pulmonary metastases, which showed that $84.6 \%$ ablated lesions were less $3 \mathrm{~cm}$ in size [15]. Also, Maxwell et al., reported that $80 \%$ ablated lesions were up to $3 \mathrm{~cm} \mathrm{[19].}$

Our results together with these studies showed that higher percentage of pulmonary lesions were less than or equal to $3 \mathrm{~cm}$ in size but differ in the percentage that could be attributed to the difference in sample size in each individual study. Moreover, we found significant relation between pre-ablation lesion size and treatment outcome $(p=0.018)$ with successful tumor ablation was significant statistically higher with lesions of maximal axial diameter up to $3 \mathrm{~cm}(93.2 \%)$ in comparison to lesions of more than $3 \mathrm{~cm}$ in maximal axial diameter $(37.5 \%)$ and this was the same finding of these forementhioned studies. This may reflect that, the achievement of an adequate ablation zone covering the whole lesion including a safety margins is extremely important to ensure adequate ablation of lung lesions.

Central and perihilar lesions had a significantly higher incidence of recurrence after ablation. This could be attributed to the "current-sink effect" caused by pulmonary arteries, which are larger and more aggregated at the hilum or the center of the lung [15].

In the current study about $86.5 \%$ of the lesions were peripherally located and $13.5 \%$ of the lesions are centrally located in relation to lung hilum with a statically significant relation between lesion location in relation to lung hilum and treatment outcome ( $p=0.019)$ with better outcome seen in peripheral lesions $(93.3 \%)$ than central lesions $(28.6 \%)$.

Vogl et al., showed that $77 \%$ were peripherally located while $23 \%$ were centrally located with significant relation with ablation outcome and more successful ablation for peripheral lesions than for centrally located lesions $(p=.002)$ [15]. Healey et al., stated that only 20 lesions out of the 108 lung lesions were centrally located while 28 were middle and 59 peripheral masses [18].

These studies together with our study concluded that most of ablated lesions were peripherally located with statistically significant relation with treatment outcome beside difference in percentage between studies and difference in individual lung preference.

Although side effects and complications related to percutaneous thermal ablation can occur [20], in the present study MWA related complications were observed in $32.65 \%$ of cases, none of which were considered life threatening for the patients. This data reinforces the concept that MWA of lung tumors is a safe procedure when performed by trained experts.

In most large studies the incidence of pneumothorax after MWA vary widely, ranging between $8.5-63 \%$ and are similar to those reported after RFA, ranging between $11 \%$ and $67 \%$ [15,21-27]. In our study $13.5 \%$ (7/52) of sessions were complicated by pneumothorax during MWA and this going with the range results of these studies but our low percentage could be due to high experienced interventional radiologists whom did the procedure as 
well as for good selection of cases through our multidisciplinary tumor team and considering the technique low invasive one.

There have been various studies that described the management of pneumothorax complicating a variety of thoracic interventions, particularly lung biopsy and thoracic ablation therapy [22,28-32]

Our cases were managed conservatively and with manual air evacuation by $5 \mathrm{~F}$ or $10 \mathrm{~F}$ catheters, but no intercostal tube was placed. The main cause for pneumothorax seems to be associated with the insertion of the antenna and not with the thermal effect of the ablation [33].

In the current study, significant risk factors associated with the development of pneumothorax, they were: (A) Age of more than 60 years, (B) Underlying emphysema, (C) Lesions smaller than $3 \mathrm{~cm}$, (D) Basal pulmonary lesions, (E) Traversing aerated lung parenchyma in the needle track for a distance $>2.6 \mathrm{~cm}$, and (F) Crossing a major pulmonary fissure in the track of ablation. These results are comparable to other studies, who agreed that tumors located in the lower parts of the lungs (higher mobility), the traversal of lung fissures and lung emphysema are also associated with an increased pneumothorax risk [26,34-36].

Delayed pneumothorax should be guarded adequately post ablation. However, we didn't experience any delayed pneumothorax post MWA.

Pulmonary hemorrhage can occur by damaging an intrapulmonary or intercostal blood vessel. An intrapulmonary hemorrhage appears as a rapidly expanding GGO starting from the antenna and can be associated with hemoptysis; however, the hemorrhage is usually self-limiting, and no action is needed [33]. In the current study; only $9.6 \%$ of patient had peri-procedural pulmonary hemorrhage. They were self-limited and didn't need intervention.

This study had some limitations; the small sample size, the studied patients is heterogeneous, including primary and metastatic pulmonary tumors with variable histological types and tumor dimensions which may affect ablation outcome in addition to the short time of study with short imaging followup despite being prospective in nature which may affect the survival results of patients.

\section{Conclusion:}

Microwave ablation therapy is a safe effective minimally invasive tool for treatment of pulmonary tumors and considered a useful option in the mul- timodality treatment of patients with in-operable lung cancer. Compared to RFA, it creates larger, more spherical and less time-consuming ablation zones and is less susceptible to the heat sink effect with same complication rate. The efficacy of treatment is determined mainly by preablation tumor size and location in relation to the hilum.

\section{References}

1- DAVIDSON R.S., NWOGU C.E., BRENTJENS, et al. The surgical management of pulmonary metastasis: Current concepts, Surg. Oncol., 10: 35-42, 2001.

2- LABOW D.M., BUELL J.E., YOSHIDA A., et al.: Isolated pulmonary recurrence after resection of colorectal hepatic metastases-is resection indicated? Cancer J., 8: 342-7, 2002.

3- SIRZÉN F., KJELLÉN E., SÖRENSON S., et al.: A systematic overview of radiation therapy effects in nonsmall cell lung cancer, Acta. Oncol., 42: 493-515, 2003.

4- VOGL T.J., NAGUIB N.N., GRUBER-ROUH T., et al.: Microwave Ablation of Lung Tumours-Clinical Update. European Oncology \& Haematology J., 8 (3): 192-5, 2012.

5- JIN G.Y., LEE J.M., LEE Y.C., et al.: Primary and secondary lung malignancies treated with percutaneous radiofrequency ablation: Evaluation with follow-up helical CT. A.J.R. Am. J. Roentgenol., 183: 1013-20, 2004.

6- VOGL T.J., NAGUIB N.N., LEHNERT T., et al.: Radiofrequency, microwave and laser ablation of pulmonary neoplasms: Clinical studies and technical considerationsreview article. Eur. J. Radiol., 77: 346-57, 2011.

7- SANTOS R.S., GAN J., OHARA C.J., et al.: Microwave ablation of lung tissue: Impact of single-lung ventilation on ablation size. Ann. Thorac. Surg., 90: 1116-9, 2010.

8- BRACE C.L.: Radiofrequency and microwave ablation of the liver, lung, kidney, and bone: What are the difference? Curr. Probl. Diagn. Radiol., 38: 135-43, 2009.

9- BRACE C.L., DIAZ T.A., HINSHAW J.L., et al.: Tissue contraction caused by radiofrequency and microwave ablation: A laboratory study in liver and lung. J. Vasc. Interv. Radiol., 21: 1280-6, 2010.

10-FURUKAWA K., MIURA T., KATO Y., et al.: Microwave coagulation therapy in canine peripheral lung tissue. J. Surg. Res., 123: 245-50, 2005.

11- KWAN S.W., MORTELL K.E., TALENFELD A.D. and BRUNNER M.C.: Thermal ablation matches sublobar resection outcomes in older patients with early-stage nonsmall cell lung cancer. J. Vasc. Interven. Radiol., 25 (1): 1-9 e1, 2014.

12- ZHONG L., SUN S., SHI J., et al.: Clinical analysis on 113 patients with lung cancer treated by percutaneous CT-guided microwave ablation. J. Thorac. Dis., 9: 5907, 2017.

13- FENG SHI, GUANGXIAO LI, ZEJIAN ZHOU, et al.: Microwave ablation versus radiofrequency ablation for the treatment of pulmonary tumors. Oncotarget, Vol. 8, (No. 65), 109791-8, 2017. 
14- IERARDI A.M., A. COPPOLA, et al.: "Treatment of lung tumours with high-energy microwave ablation: A singlecentre experience." Medical oncology, 34 (1): 5, 2017.

15- VOGL, et al.: VOGL T.J., NAGUIB N.N., GRUBERROUH T., et al.: Microwave ablation therapy: Clinical utility in treatment of pulmonary metastases. Radiology, 261: 643-51, 2011.

16- LU Q., CAOW., HUANG L., et al.: CT-guided percutaneousmicrowave ablation of pulmonarymalignancies: Results in 69 cases. World journal of surgical oncology, 10: 80, 2012.

17- ZHENG A., YE X., YANG X., HUANG G. and GAI Y.: Local Efficacy and Survival after Microwave Ablation of Lung Tumors: A Retrospective Study in 183 Patients. J. Vasc. Interv. Radiol., 27 (12): 1806-14, 2016.

18- HEALEY T.T., MARCH B.T., BAIRD G. and DUPUY D.E.: Microwave Ablation for Lung Neoplasms: A Retrospective Analysis of Long-Term Results. J. Vasc. Interv. Radiol., 28 (2): 206-11, 2016.

19- MAXWELL A.W. and HEALEY T.T.: DE. Percutaneous Thermal Ablation for Small-Cell Lung Cancer: Initial Experience with Ten Tumors in Nine Patients. J. Vasc. Interv. Radiol., 27 (12): 1815-21, 2016.

20- PUSCEDDU C., MELIS L., SOTGIA B., GUERZONI D., PORCU A. and FANCELLU A.: Usefulness of percutaneous microwave ablation for large non-small cell lung cancer: A preliminary report. Oncol. Lett., 18 (1): 65966, 2019.

21- WOLF F.J., GRAND D.J., MACHAN J.T., et al.: Microwave Ablation of Lung Malignancies: Effectiveness, CT Findings, and Safety in 50 Patients. Radiology, 247: 8719, 2008.

22- BELFIORE G., RONZA F., BELFIORE M.P., et al.: Patients' survival in lung malignancies treated by microwave ablation: Our experience on 56 patients. European journal of radiology, 82: 177-81, 2013.

23- CARRAFIELLO G., MANGINI M., FONTANA F., et al.: Microwave ablation of lung tumours: Single-centre preliminary experience. La Radiologia medica, 119: 7582, 2014.

24- WEI Z., YE X., YANG X., et al.: Microwave ablation in combination with chemotherapy for the treatment of advanced non-small cell lung cancer. Cardiovascular and interventional radiology, 38: 135-42, 2015.

25- YANG X., YE X., ZHENG A., et al.: Percutaneous microwave ablation of stage Imedically inoperable non-small cell lung cancer: Clinical evaluation of 47 cases. Journal of surgical oncology, 110: 758-63, 2014.
26- HIRAKI T., GOBARA H., FUJIWARA H., et al.: Lung cancer ablation: Complications. Seminars in interventional radiology, 30: 169-75, 2013.

27- De BAERE T., AUPERIN A., DESCHAMPS F., et al.: Radiofrequency ablation is a valid treatment option for lung metastases: Experience in 566 patients with 1037 metastases. Annals of oncology: Official journal of the European Society for Medical Oncology/ESMO, 26: 987 91, 2015.

28- DUPUY D.E., ZAGORIA R.J., AKERLEY W., MAYOSMITH W.W., KAVANAGH P.V. and H. SAFRAN: Percutaneous radiofrequency ablation of malignancies in the lung. Am. J. Roentgenol., 174: 57-9, 2000.

29- YEOW K.M., SU I.H., PAN K.T., TSAY P.K., LUI K.W., CHEUNG Y.C. and CHOU A S.B.: Risk factors of pneumothorax and bleeding multivariate analysis of $660 \mathrm{CT}$ guided coaxial cutting needle lung biopsies. Chest, 126: 748-75, 2004.

30- YAMAGAMI T., KATO T., HIROTA T., YOSHIMATSU R., MATSUMOTO T. and NISHIMURA T.: Pneumothorax as a complication of percutaneous radiofrequency ablation for lung neoplasms. J. Vasc. Interv. Radiol., 17: 1625-9, 2006

31- SIMON C.J., DUPUY D.E., DIPETRILLO T.A., SAFRAN H.P., GRIECO C.A., NG T. and MAYO-SMITH W.W.: Pulmonary radiofrequency ablation: Long-term safety and efficacy in 153 patients. Radiology, 243: 268-75, 2007.

32- VOGL, ROMINA ECKERT, NAGY N.N. NAGUIB, et al.: Thermal Ablation of Colorectal Lung Metastases: Retrospective Comparison Among Laser-Induced Thermotherapy, Radiofrequency Ablation, and Microwave Ablation. A.J.R., 207: 1340-9, 2016.

33- VOGL T.J., NOUR-ELDIN N.A. and ALBRECHT M.H.: Thermal Ablation of Lung Tumors: Focus on Microwave Ablation. Rofo., 189 (9): 828-43, 2017.

34- ZHENG A., WANG X., YANG X., et al.: Major complications after lung microwave ablation: A single-center experience on 204 sessions. The Annals of thoracic surgery, 98: 243-8, 2014.

35- NOUR-ELDIN N.E., NAGUIB N.N., SAEED A.S., et al.: Risk factors involved in the development of pneumothorax during radiofrequency ablation of lung neoplasms. American journal of roentgenology, 193: W43-W48, 2009.

36- HIRAKI T., TAJIRI N., MIMURA H., et al.: Pneumothorax, pleural effusion, and chest tube placement after radiofrequency ablation of lung tumors: Incidence and risk factors. Radiology, 241: 275-83, 2006. 


\section{دور الإجتثاث بالميكرويف فى علاج آورام الرئة}

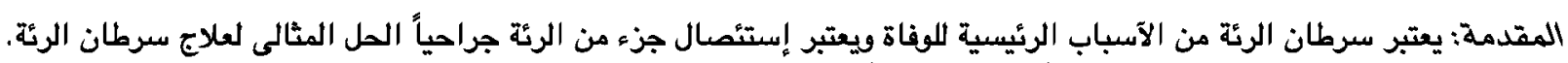

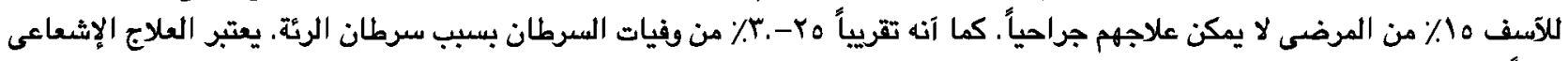

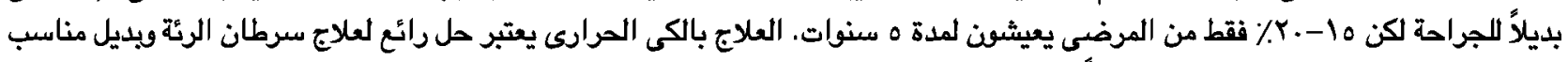

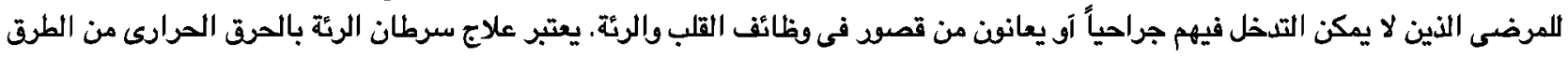

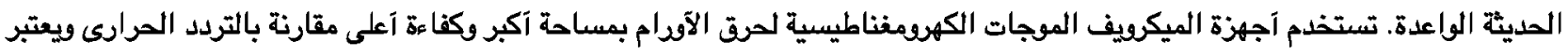

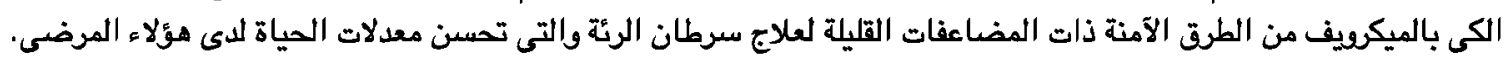

الهدف من البحث: يهدف البحث إلى تقييم إستخدام الكى بالميكرويف فى علاج سرطان الرئة.

المواد وطرق البحث: أجريت هذه الدراسة بقسم الآشعة بمستشفيات جامعة جوته - فرانكفقرت - آلمانيا الإتحادية للمرضى الذين يعانون من آقدام الرئة ولا يمكن علاجهم جراحياً.

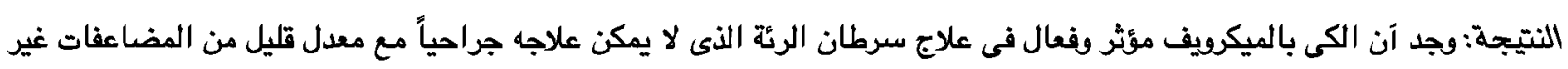

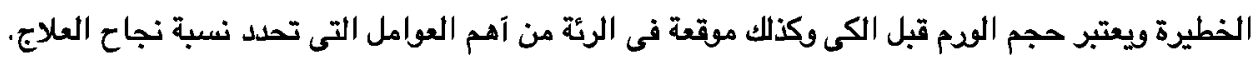

